OPEN ACCESS

Edited by:

Laigeng Li,

Shanghai Institutes for Biological Sciences (CAS), China

Reviewed by:

Zhaojun Ding

Shandong University, China María Serrano,

Universidad Miguel Hernández de Elche, Spain

*Correspondence:

Daping Xu

gzfsrd@163.com

Specialty section: This article was submitted to

Plant Physiology,

a section of the journal

Frontiers in Plant Science

Received: 07 November 2018 Accepted: 15 February 2019

Published: 08 March 2019

Citation:

Cui Z, Yang Z and Xu D (2019) Synergistic Roles of Biphasic Ethylene

and Hydrogen Peroxide

in Wound-Induced Vessel Occlusions and Essential Oil Accumulation

in Dalbergia odorifera.

Front. Plant Sci. 10:250.

doi: 10.3389/fpls.2019.00250

\section{Synergistic Roles of Biphasic Ethylene and Hydrogen Peroxide in Wound-Induced Vessel Occlusions and Essential Oil Accumulation in Dalbergia odorifera}

\author{
Zhiyi Cui, Zengjiang Yang and Daping $X u^{*}$ \\ Research Institute of Tropical Forestry, Chinese Academy of Forestry, Guangzhou, China
}

The heartwood of Dalbergia odorifera ( $D$. odorifera), named "Jiang Xiang" in traditional Chinese medicine, is highly valuable. Mechanical wounding induced the production of "Jiang Xiang" in D. odorifera. Ethylene and hydrogen peroxide $\left(\mathrm{H}_{2} \mathrm{O}_{2}\right)$ are proposed to play vital roles in wound signaling. However, little is known about the role of ethylene or $\mathrm{H}_{2} \mathrm{O}_{2}$ in the wound-induced formation of vessel occlusions and biosynthesis of "Jiang Xiang" in D. odorifera. In this study, the pruning of $D$. odorifera saplings resulted in the synergistic biosynthesis of biphasic ethylene and $\mathrm{H}_{2} \mathrm{O}_{2}$, which was followed by formation of vessel occlusions and "Jiang Xiang" in the pruned stems. In this process, the $\mathrm{H}_{2} \mathrm{O}_{2}$ production stimulated higher biosynthesis of ethylene. Treatments with aminoethoxyvinylglycine (AVG), an inhibitor for ethylene biosynthesis and ascorbate acid (AsA), a scavenger of $\mathrm{H}_{2} \mathrm{O}_{2}$, markedly reduced the production of ethylene and $\mathrm{H}_{2} \mathrm{O}_{2}$, respectively, and the corresponding the percentage of vessels with occlusions (PVO), oil content, and the amount of "Jiang Xiang" formed. These results indicate that ethylene and $\mathrm{H}_{2} \mathrm{O}_{2}$ might be important wound signals in $D$. odorifera that induce vessel occlusions and formation of "Jiang Xiang," and thus ethylene and $\mathrm{H}_{2} \mathrm{O}_{2}$ might play vital roles in "Jiang Xiang" formation in pruned stems of $D$. odorifera.

Keywords: mechanical wound, essential oil, ethylene, hydrogen peroxide, heartwood, Dalbergia odorifera

\section{INTRODUCTION}

Dalbergia odorifera T. Chen (D. odorifera) is a medium-sized tree from the Leguminosae family, and famous for its heartwood, one of the best rosewoods (Figure 1A) in the world. The heartwood of D. odorifera, named "Jiang Xiang" in traditional Chinese medicine, has been widely used as Chinese Pharmacopeia for centuries to stop bleeding, regulate the "Qi," dissipate blood stasis, and relieve pain (Yukihiro et al., 1985; Cheng et al., 1998; Wang et al., 2000; Sugiyama et al., 2002; Choi et al., 2009; Liu et al., 2017). However, the heartwood of D. odorifera forms relatively slowly when trees are more than 6-years-old, and the percentage of heartwood over total stemwood is very small (Ma et al., 2017); thus, study on the promotion of heartwood formation is encouraged (Cui et al., 2017). 


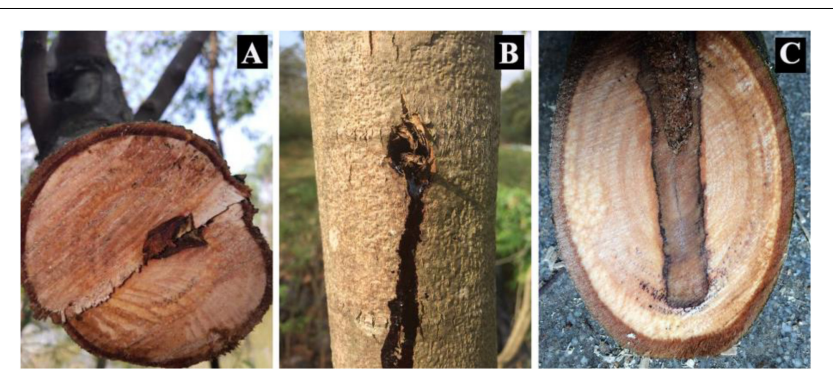

FIGURE 1 | Image description of "JiangXiang" of Dalbergia odorifera. (A) Represents the natural heartwood (wild "JiangXiang"), which forms very slowly. (B) Represents tree trunk suffering from mechanical wound.

(C) Represents mechanical wound induced "Jiang Xiang" (discolored wood).

Meng et al. (2010) found that mechanical wounding induced the production of "Jiang Xiang" in D. odorifera (Figures 1B,C). Similar results were also observed in Santalum album (Wei et al., 2000) and Aquilaria sinensis (Chen et al., 2012; Wang et al., 2016). Xylem cells destined to form tracheids or vessel members, which provide the conduit for water and mineral transportation, undergo apoptosis (Lucas and Liu, 2017). Vessel occlusions develop in the conduit lumen in response to mechanical wounding in many species for wound sealing and reducing the risk of pathogen intrusion (Saitoh et al., 1993; Dute et al., 1999). Although xylem vessels are primarily dead cells at maturity, they are in contact and communication, especially via pits, with living perivascular parenchyma cells that surround vessels. Perivascular parenchyma cells are active in regulating xylem vessels contents. After wounding or fungal pathogen infection, heartwood substances accumulate in the perivascular parenchyma cells, and are released into the infected vessel lumen to format vessel occlusions for restricting the vessel ingress of the fungus (Zhang et al., 2010).

Ethylene is an important regulator of plant development and growth, and is known to be associated with plant defense (Hou et al., 2013; Savatin et al., 2014). Ethylene production in response to wounding has been demonstrated in a wide range of species. Mechanical wounding induced mandarin (Citrus unshiu) (Hyodo and Nishino, 1981), tomato (Solanum lycopersicum) (O’Donnell et al., 1996), winter squash (Cucurbita maxima) (Kato et al., 2000) and lettuce (Lactuca sativa) (Ke and Saltveit, 2010) to regulate the expression of ACS and ACO genes in ethylene synthesis. Sun et al. (2007) found that pruning induced ethylene release and tylose development in grape (Vitis vinifera) stems. Van Doorn et al. (1991) also reported that tylose development was reduced in the cut stem of lilac (Syringa vulgaris) flowers treated with ethylene inhibitors.

Reactive oxygen species (ROS), which include hydrogen peroxide $\left(\mathrm{H}_{2} \mathrm{O}_{2}\right)$, superoxide and hydroxyl radicals, have been proposed to play a vital role in wound signaling (OrozcoCardenas and Ryan, 1999; Ross et al., 2006; Angelini et al., 2008; Mittler et al., 2011). Studies on ROS are always represented by $\mathrm{H}_{2} \mathrm{O}_{2}$ due to its longer half-life (Levine et al., 1994; D’Autréaux and Toledano, 2007). $\mathrm{H}_{2} \mathrm{O}_{2}$ generated in response to wounding can not only be used directly as antimicrobial agents, but also acts as both local and diffusible signal molecules for inducing formation of defense structures, such as callose (Luna et al., 2011) and vessel occlusions (Lorrain et al., 2004; Zhang et al., 2014). $\mathrm{H}_{2} \mathrm{O}_{2}$ can also mediate the elicitor-induced accumulation of secondary metabolites, such as isoflavonoid glyceollin in soybean (Glycine max) (Degousee et al., 1994; Guo et al., 1998), p-coumaroyloctopamine in potato tubers (Solanum tuberosum) (Matsuda et al., 2001), capsidiol in tobacco (Nicotiana tabacum) (Perrone et al., 2003), and sesquiterpenes in Aquilaria sinensis (Zhang et al., 2014).

Our field experiment showed that direct injection of ethylene and $\mathrm{H}_{2} \mathrm{O}_{2}$ into the stems of $D$. odorifera resulted in vessel occlusions and formation of "Jiang Xiang," and it was observed that mechanical wounding induced the production of "Jiang Xiang" in D. odorifera. Ethylene and $\mathrm{H}_{2} \mathrm{O}_{2}$ have been proposed to play vital roles in wound signaling, but little information is available on the roles of ethylene and $\mathrm{H}_{2} \mathrm{O}_{2}$ in the wound-induced formation of vessel occlusions and biosynthesis of "Jiang Xiang" in D. odorifera. Thus, this study was conducted to investigate whether ethylene or $\mathrm{H}_{2} \mathrm{O}_{2}$ are involved in wounding-induced vessel occlusions and "Jiang Xiang” formation in D. odorifera.

\section{MATERIALS AND METHODS}

\section{Plant Materials and Experimental Design}

Three-year-old saplings of $D$. odorifera were selected to grow in a greenhouse at the Research Institute of Tropical Forestry, Chinese Academy of Forestry, Guangzhou City, Guangdong, China. The saplings were grown under day/night temperatures of $31 \pm 3 / 24 \pm 4^{\circ} \mathrm{C}$, respectively. The saplings were $1.68 \pm 0.32 \mathrm{~m}$ in height, with a stem diameter of $2.64 \pm 0.21 \mathrm{~cm}$ at a height of $10 \mathrm{~cm}$ above the ground.

The sapling stems were cut through at $10 \mathrm{~cm}$ above the ground in air, water, $0.5 \mathrm{mM}$ aminoethoxyvinylglycine (AVG) (an inhibitor of ethylene biosynthesis) or $1 \mathrm{mM}$ ascorbic acid (AsA) (the special scavenger of $\mathrm{H}_{2} \mathrm{O}_{2}$ ). The cut ends were soaked in the water, AVG or AsA for $2 \mathrm{~h}$ before being exposed to air.

\section{Ethylene Measurement}

Ethylene production in pruned stems was estimated by measuring the ethylene evolved from the cut stem end. To collect gas evolved from the cut, a 5-cm-long rubber tube was attached immediately after each treatment and gas was collected in a 5-mL syringe. Each ethylene sample was collected for half an hour before measurement. The ethylene concentration in the accumulated gas in the syringe was measured at $0.5,1,2,4,6$, $9,12,15,18,24,30,36$ and $48 \mathrm{~h}$ after treatment, respectively, using an analytical gas chromatograph (Shimazawa, Japan). Five replicate stems were used for the ethylene measurement with each treatment and ethylene production is reported as the concentration in the 5-mL headspace. Because of slight differences in the diameter among the shoots, ethylene concentration data were normalized to a shoot with a $2.64-\mathrm{cm}$ diameter (approximate mean diameter). 
The gas chromatograph was equipped with Column SE-54 $(30 \mathrm{~m} \times 0.32 \mathrm{~mm} \times 0.25 \mu \mathrm{m})$ and column temperature was $70^{\circ} \mathrm{C}$. The temperatures of the $\mathrm{H}^{+}$-FID flame detector and vaporization chamber were $100^{\circ} \mathrm{C}$. Helium was used as carrier gas at a flow rate of $50 \mathrm{~mL} \mathrm{~min}-1$. Hydrogen was used as fuel gas at a flow rate of $60 \mathrm{~mL} \mathrm{~min}^{-1}$. The flow rate of air was $400 \mathrm{~mL} \mathrm{~min}^{-1}$ and the split ratio was 10:1.

\section{Hydrogen Peroxide Assay}

A 1.1-cm-thick stem was collected from the end of each treated stem. Then, a 1-mm-thick section at the end of the cut stem was abandoned, and five 2 -mm-thick sections were collected at the positions of $2,4,6,8$, and $10 \mathrm{~mm}$ from the pruning end. Stem sections were taken at $0,1,2,6,12,24$ and $36 \mathrm{~h}$ after pruning. They were transferred immediately on cutting to liquid nitrogen and stored at $-80^{\circ} \mathrm{C}$ for measurement of endogenous $\mathrm{H}_{2} \mathrm{O}_{2}$. For each sampling, five replicate stems were used for the $\mathrm{H}_{2} \mathrm{O}_{2}$ measurement with each treatment (a total of 140 stems). The samples were immersed in liquid nitrogen and ground to a powder with a pestle and mortar. $\mathrm{H}_{2} \mathrm{O}_{2}$ was analyzed by enzyme-linked immunosorbent assay (ELISA) (Sangon Biotech, Shanghai, China) as described previously with minor modification (Hong et al., 2017). Briefly, the samples, standards, and HRP-labeled detection antibody were added successively in the microporous plate pre-coated with $\mathrm{H}_{2} \mathrm{O}_{2}$ capture antibody, then incubated and thoroughly washed. The substrate tetramethylbenzidine (TMB) was converted to blue by the peroxidase catalysis and finally converted to yellow under the action of an acid. $\mathrm{H}_{2} \mathrm{O}_{2}$ concentrations in the samples were positively correlated with the color intensity. The absorbance (OD value) was measured with a microplate reader at a wave-length of $450 \mathrm{~nm}$ to calculate the $\mathrm{H}_{2} \mathrm{O}_{2}$ concentration in the sample.

\section{Vessel Occlusion Assessment}

Sections were prepared from stems as described in section "Hydrogen Peroxide Assay". For each sampling, five replicate stems were used for assessment of vessel occlusions with each treatment (a total of 140 stems). The samples were collected and fixed in formalin acetic acid-alcohol (FAA) for assessment of vessel occlusions at $0,1,2,3,4,5$ and 6 weeks, respectively. The percentage of vessel occlusions (PVO) was assessed as previously described (Sun et al., 2007). Briefly, transverse sections $(20 \mu \mathrm{m}$ in thickness) were prepared with a sliding microtome (Leica RM2255, Germany). The sections were temporarily mounted with a cover slip in water, then observed under light microscopy (Olympus BX51, Japan) equipped with a digital camera (Pixera Pro 600ES, United States). Five areas, each containing 20-30 vessels, were chosen randomly for analysis. The analysis of each replication (cut stem) included 100-150 vessels.

\section{Essential Oil Assessment}

The samples were collected as mentioned above for assessment of essential oil at $0,1,2,3,4,5$, and 6 weeks, respectively. For each sampling, five replicate stems were used for assessment of essential oil with each treatment (a total of 140 stems). The samples were immediately immersed in liquid nitrogen and ground to a powder with a pestle and mortar. For each treatment, $1 \mathrm{~g}$ powdered stem samples were weighed, immersed in $30 \mathrm{ml}$ petroleum ether and shaken for $24 \mathrm{~h}$. After filtration and concentration (Concentrator 5301, Eppendorf, Germany), essential oil was obtained and the oil content was also calculated.

Essential oil from the 6 week harvest was used for GC-MS with an Agilent 6890 N-5975 I system with an Innowax DB$5 \mathrm{MS}$ column $(30 \mathrm{~m} \times 0.25 \mathrm{~mm}, 0.25 \mu \mathrm{m}$ film thickness $)$. Helium was used as carrier gas at a flow rate of $1 \mathrm{~mL} \mathrm{~min}^{-1}$. Oven temperature was programmed to $70^{\circ} \mathrm{C}$ for $1 \mathrm{~min}$, raised to $250^{\circ} \mathrm{C}$ at a rate of $8^{\circ} \mathrm{C} \mathrm{min}{ }^{-1}$, and kept constant at $250^{\circ} \mathrm{C}$ for $15 \mathrm{~min}$. Mass spectra were recorded at $70 \mathrm{eV}$ with the mass range $m / z$ 35 to 450 . The identification of essential oil components was done by computer matching against NIST and Wiley GC-MS Library or comparing the retention times of oil components with standard samples.

\section{Statistical Analysis}

Data were calculated based on combined averages from five individual saplings $(n=5)$ per treatment. The plots for the graphs were generated in SigmaPlot 10.0 (Systat, United States). The significance of differences among treatments was evaluated with Duncan's multiple range tests using the data processing software SPSS 17.0 (IBM, NY, United States).

\section{RESULTS}

\section{Wounding Induced Enhanced Ethylene Production}

Whether stems were pruned in air or in water, production of ethylene increased in response to wounding. Ethylene production increased in a biphasic manner with peaks at about $6 \mathrm{~h}$ and $18 \mathrm{~h}$ after pruning and an intervening decline to the initial level at $12 \mathrm{~h}$ (Figure 2). The second peak was about 3-times

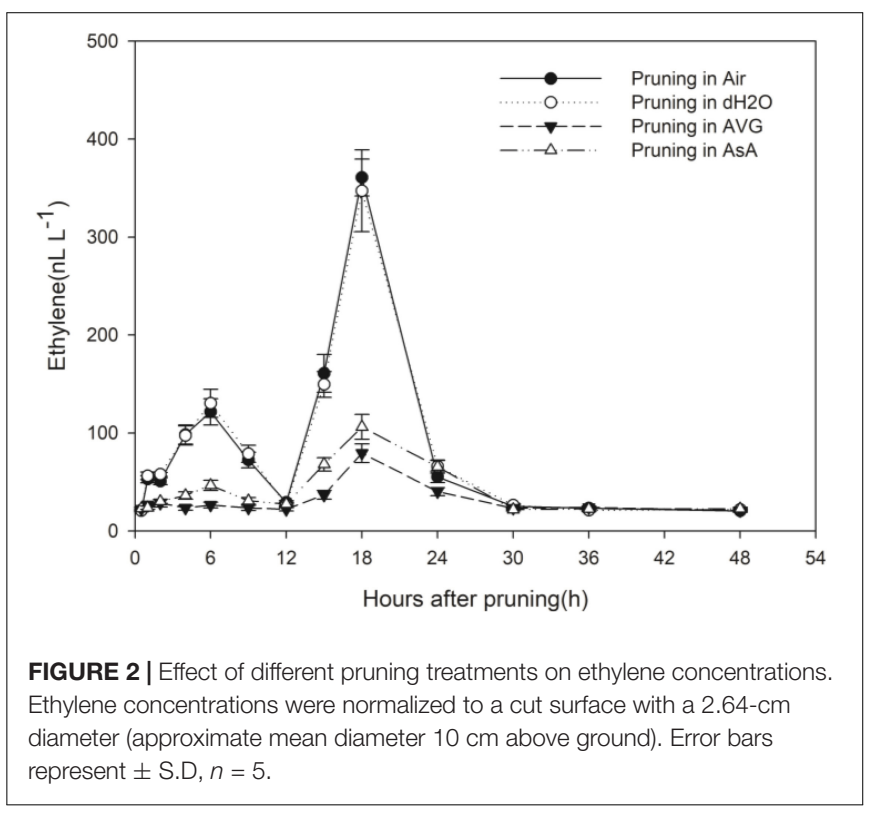


greater than the first peak and 15-times greater than the initial concentration. By $30 \mathrm{~h}$ after pruning, the ethylene concentration was again at the initial level where it remained with a slight diurnal oscillation (Figure 2).

In contrast, the pattern of ethylene production from the pruned end of stems treated with AVG or with AsA was dramatically different from the treatments in air and water. These two treatments almost eliminated the first rise in ethylene concentration; the second increase was greatly reduced too. The second peak value was 360.82 and $347.30 \mathrm{~nL} \mathrm{~L}^{-1}$ in stems pruned in air and in water, respectively, while it was only 79.41 and $106.22 \mathrm{~nL} \mathrm{~L}^{-1}$ in stems pruned in AVG and in AsA, respectively (Figure 2). Ethylene production induced by wounding was greatly suppressed in the presence of AVG and AsA.

\section{Wounding Induced Enhanced $\mathrm{H}_{2} \mathrm{O}_{2}$ Production}

Wound-induced $\mathrm{H}_{2} \mathrm{O}_{2}$ production was measured from 0 to $36 \mathrm{~h}$ after pruning at 5 depths from the wound surface. $\mathrm{H}_{2} \mathrm{O}_{2}$ also produced in a biphasic manner, peaked at about $2 \mathrm{~h}$ and $12 \mathrm{~h}$ after pruning and declined to the initial level at $6 \mathrm{~h}$ and $24 \mathrm{~h}$ (Figure 3). The second peak of $\mathrm{H}_{2} \mathrm{O}_{2}$ production was about 2.5 times of the first peak and almost 40 times higher than the initial concentration. Generally, $\mathrm{H}_{2} \mathrm{O}_{2}$ production decreased with distance from the wound surface (Figure 3). The peak in $\mathrm{H}_{2} \mathrm{O}_{2}$ concentration at $12 \mathrm{~h}$ after pruning decreased with distance from the wounded surface, ranging from $98.60 \mathrm{nmol} \mathrm{g}^{-1} \mathrm{FW}$ at $2 \mathrm{~mm}$ to $29.65 \mathrm{nmol} \mathrm{g}^{-1} \mathrm{FW}$ at $10 \mathrm{~mm}$ (Figure 3A).

Wound-induced $\mathrm{H}_{2} \mathrm{O}_{2}$ production of the treatment with AsA (Figure 3D) was greatly reduced compared to the treatments in air and water (Figures 3A,B). However, no significant difference was found in $\mathrm{H}_{2} \mathrm{O}_{2}$ production between the treatments in air, water and AVG (Figures 3A-C). The peak in $\mathrm{H}_{2} \mathrm{O}_{2}$ concentration at $12 \mathrm{~h}$ after pruning was 98.60, 96.75 and $97.68 \mathrm{nmol} \mathrm{g}^{-1}$ FW in stems pruned in air, water and AVG, respectively. By contrast, it was only $40.82 \mathrm{nmol} \mathrm{g}^{-1} \mathrm{FW}$ in stems pruned in AsA (Figure 3). Thus, wound-induced $\mathrm{H}_{2} \mathrm{O}_{2}$ production was greatly suppressed in the presence of AsA, but not under the influence of AVG.

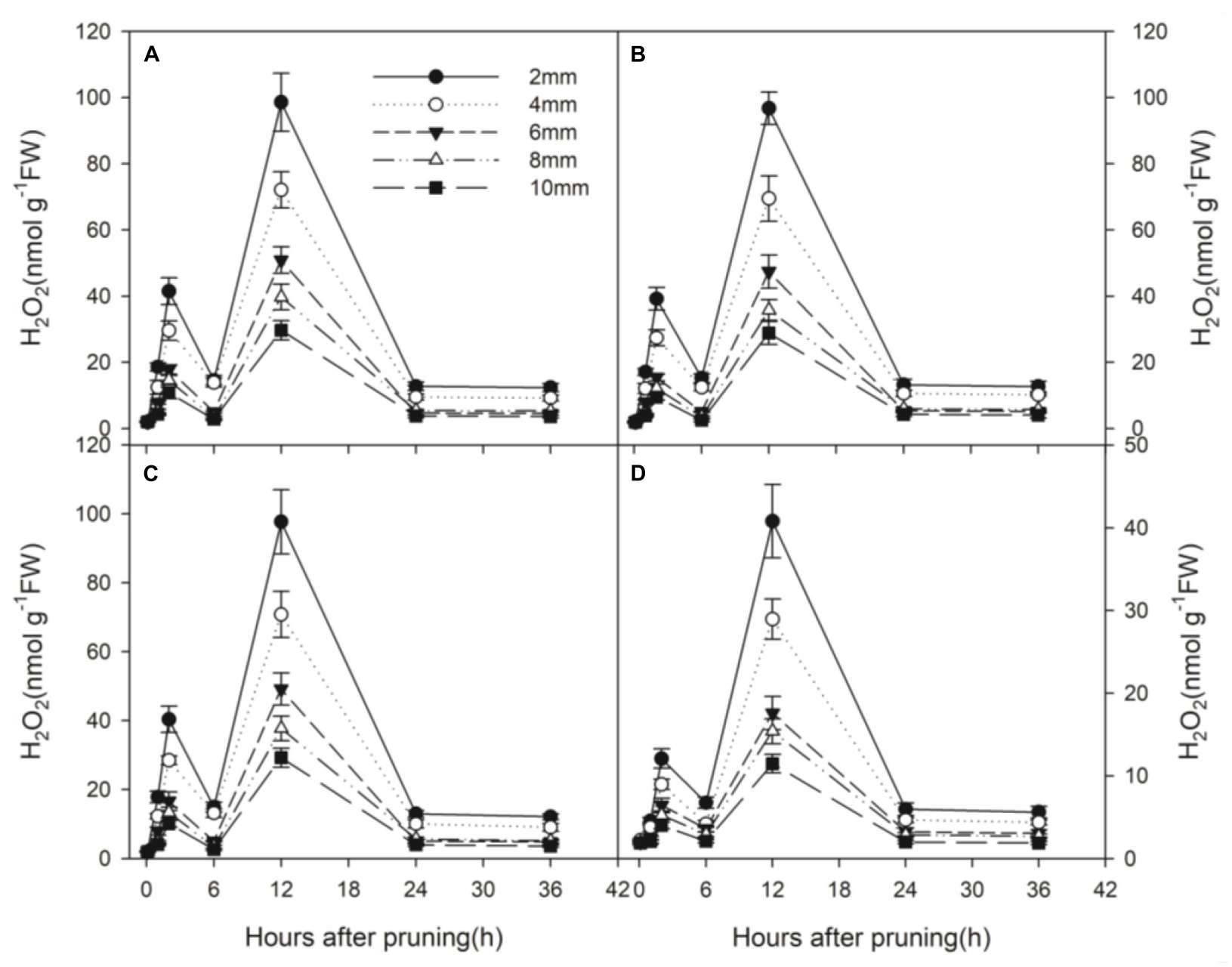

FIGURE 3 | Temporal progress in $\mathrm{H}_{2} \mathrm{O}_{2}$ concentration in xylem tissue of wounded stems at different depths (2, 4, 6, 8, and 10 mm) from the cut surface of stems pruned in air (A), water (B), AVG (C) and AsA (D). Error bars represent \pm S.D, $n=5$. 

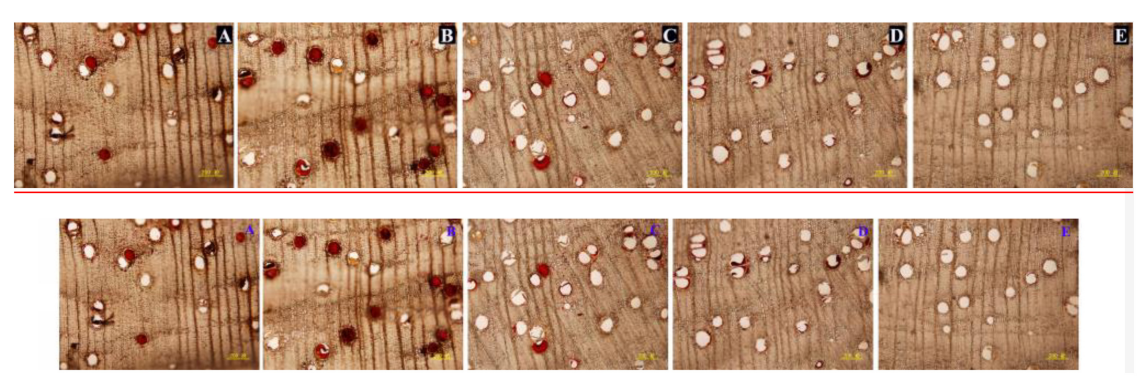

FIGURE 4 | Vessel occlusions of transverse sections at different depths from the cut surface at 6 weeks after pruning. (A-E) Represents transverse sections at 2, 4, 6,8 , and $10 \mathrm{~mm}$ from the cut surface, respectively. Scale bars $=200 \mu \mathrm{m}$.

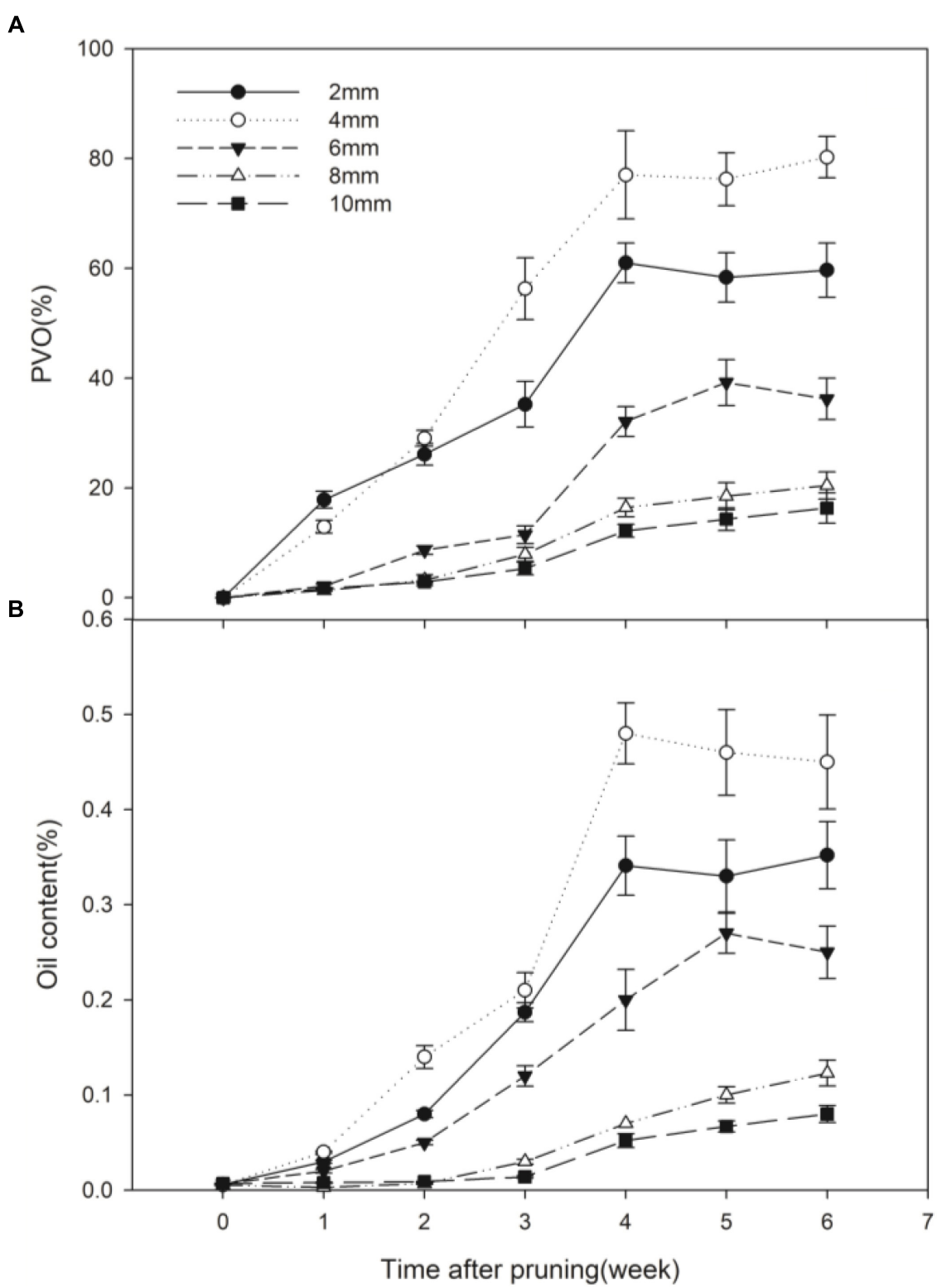

FIGURE $\mathbf{5}$ | Temporal progress in pruning-induced percentage of vessel occlusions (A) and essential oil content (B) at different depths from the cut surface in stems pruned in air. PVO, the percentage number of vessels with occlusions. Error bars represent \pm S.D, $n=5$. 


\section{Wound-Induced Vessel Occlusions and Essential Oil at Different Depths From the Cut Surface}

Prior to pruning, the D. odorifera stems had essentially no occlusions. After pruning in air, occlusions were observed in the vessel lumens, and continued production of vessel occlusions sealed some vessel lumens. A significant difference in vessel occlusions was observed between depths from the cut surface (Figure 4). The percentage of vessels with occlusions (PVO) kept increasing in the first 4 weeks after pruning. After that, the changes were small. PVO increased much faster at 2, 4 and $6 \mathrm{~mm}$ compared to 8 and $10 \mathrm{~mm}$, and PVO at $4 \mathrm{~mm}$ increased at a faster rate than other distances. Four weeks after pruning, the PVO at 2 and $4 \mathrm{~mm}$ sections reached 60.98 and $77.01 \%$, respectively, while they were only 16.43 and $12.20 \%$ for 8 and $10 \mathrm{~mm}$ sections, respectively (Figure 5A). The pattern of essential oil content was almost synchronous with that of PVO (Figure 5B).

Nine major volatiles were identified in the essential oil extracted from the samples at different depths from the wound surface. However, none of these volatiles was found in the control samples (stems prior to pruning). The relative amount of volatiles was highest at $4 \mathrm{~mm}$, and decreased significantly above and below this depth (Table 1). These results showed that wounding induced the most vessel occlusions and essential oil at $4 \mathrm{~mm}$ from the cut surface.

\section{Wound-Induced Vessel Occlusions and Essential Oil in Stems of Different Treatments}

In the stems pruned in air or water, occlusions were observed in a large number of vessels in secondary xylem (Figures 6A,B), while occlusions were absent in most of the vessels in the stems treated with AVG or AsA (Figures 6C,D). The PVO and essential oil content were markedly affected by the AVG and AsA treatments. At 6 weeks after pruning, PVO at $4 \mathrm{~mm}$ section of stems treated in air, water, AVG or AsA reached 80.24, 76.92, 19.6 and $27.46 \%$, respectively (Figure 7A). Consequently, the essential oil content was $0.45,0.47,0.13$ and $0.18 \%$ for stems treated in air, water, AVG or AsA, respectively (Figure 7B). These results indicated that suppression of wound-induced ethylene or $\mathrm{H}_{2} \mathrm{O}_{2}$ production significantly reduced vessel occlusions and essential oil content.

The kind and quantity of the volatiles in the treatment pruned in AVG or AsA also decreased significantly compared to the treatments pruned in air and water (Table 2). Similar volatiles were detected in the treatments pruned in air and water. Nine volatiles identified in wild "Jiang Xiang" was found in
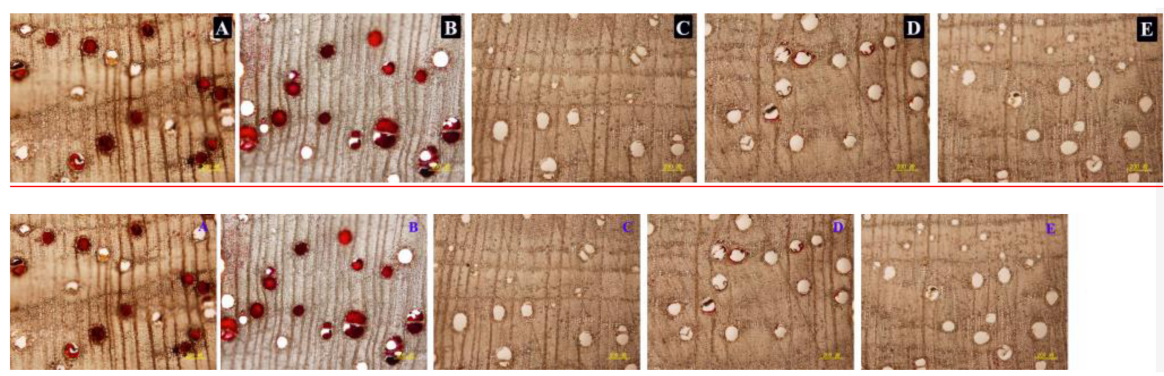

FIGURE 6 | Vessel occlusions of transverse sections at $4 \mathrm{~mm}$ from the cut surface in stems of different treatments at 6 weeks after pruning. (A-E) Represents transverse sections of treatment pruned in air, $\mathrm{dH}_{2} \mathrm{O}, \mathrm{AVG}$ or AsA and prior to pruning, respectively. Scale bars $=200 \mu \mathrm{m}$.

TABLE 1 | Chemical composition and relative amounts of essential oil from the samples at different depths from the cut surface in stems pruned in air after 6 weeks treatment.

\begin{tabular}{|c|c|c|c|c|c|c|c|}
\hline \multirow[t]{2}{*}{ No. } & \multirow[t]{2}{*}{ Compound name } & \multicolumn{6}{|c|}{ Relative amount (\%) } \\
\hline & & $2 \mathrm{~mm}$ & $4 \mathrm{~mm}$ & $6 \mathrm{~mm}$ & $8 \mathrm{~mm}$ & $10 \mathrm{~mm}$ & CK \\
\hline 1 & (E)-.beta.-Famesene & $0.02 \pm 0.00 b$ & $0.05 \pm 0.00 a$ & $-\mathrm{C}$ & $-\mathrm{C}$ & $-\mathrm{C}$ & $-\mathrm{C}$ \\
\hline 2 & alpha.-Farnesene & $0.25 \pm 0.03 a$ & $0.28 \pm 0.03 a$ & $0.07 \pm 0.01 b$ & $-\mathrm{C}$ & $-\mathrm{C}$ & $-\mathrm{C}$ \\
\hline 3 & 2-Cyclohexen-1-ol, 2-methyl-5-(1-methylethenyl)-, cis- & $0.36 \pm 0.04 b$ & $1.58 \pm 0.12 \mathrm{a}$ & $0.32 \pm 0.03 b$ & $-\mathrm{C}$ & $-\mathrm{C}$ & $-\mathrm{C}$ \\
\hline 4 & 1,5-Heptadiene, 3,3-dimethyl-, (E)- & $1.01 \pm 0.08 \mathrm{~b}$ & $1.49 \pm 0.16 a$ & $0.67 \pm 0.05 c$ & $-d$ & $-d$ & $-d$ \\
\hline 5 & 2-Isopropenyl-5-methylhex-4-enal & $0.42 \pm 0.02 b$ & $0.67 \pm 0.07 a$ & $0.38 \pm 0.04 b$ & $0.15 \pm 0.01 c$ & $-d$ & $-d$ \\
\hline 6 & 2-Cyclohexene-1-carboxaldehyde, 2,6,6-trimethyl- & $0.7 \pm 0.05 b$ & $0.92 \pm 0.06 a$ & $0.67 \pm 0.04 b$ & $0.41 \pm 0.02 c$ & $-d$ & $-d$ \\
\hline 7 & Citronellol & $0.05 \pm 0.01 b$ & $0.26 \pm 0.03 a$ & $-\mathrm{C}$ & $-\mathrm{C}$ & $-\mathrm{C}$ & $-\mathrm{C}$ \\
\hline 8 & Butanoic acid, 3-hexenyl ester, (Z)- & $1.22 \pm 0.09 b$ & $1.76 \pm 0.21 \mathrm{a}$ & $1.30 \pm 0.09 b$ & $0.75 \pm 0.05 c$ & $-d$ & $-d$ \\
\hline 9 & Nerolidol & $0.23 \pm 0.01 b$ & $0.56 \pm 0.03 a$ & $0.08 \pm 0.01 c$ & $-d$ & $-d$ & $-d$ \\
\hline
\end{tabular}
deviation. 


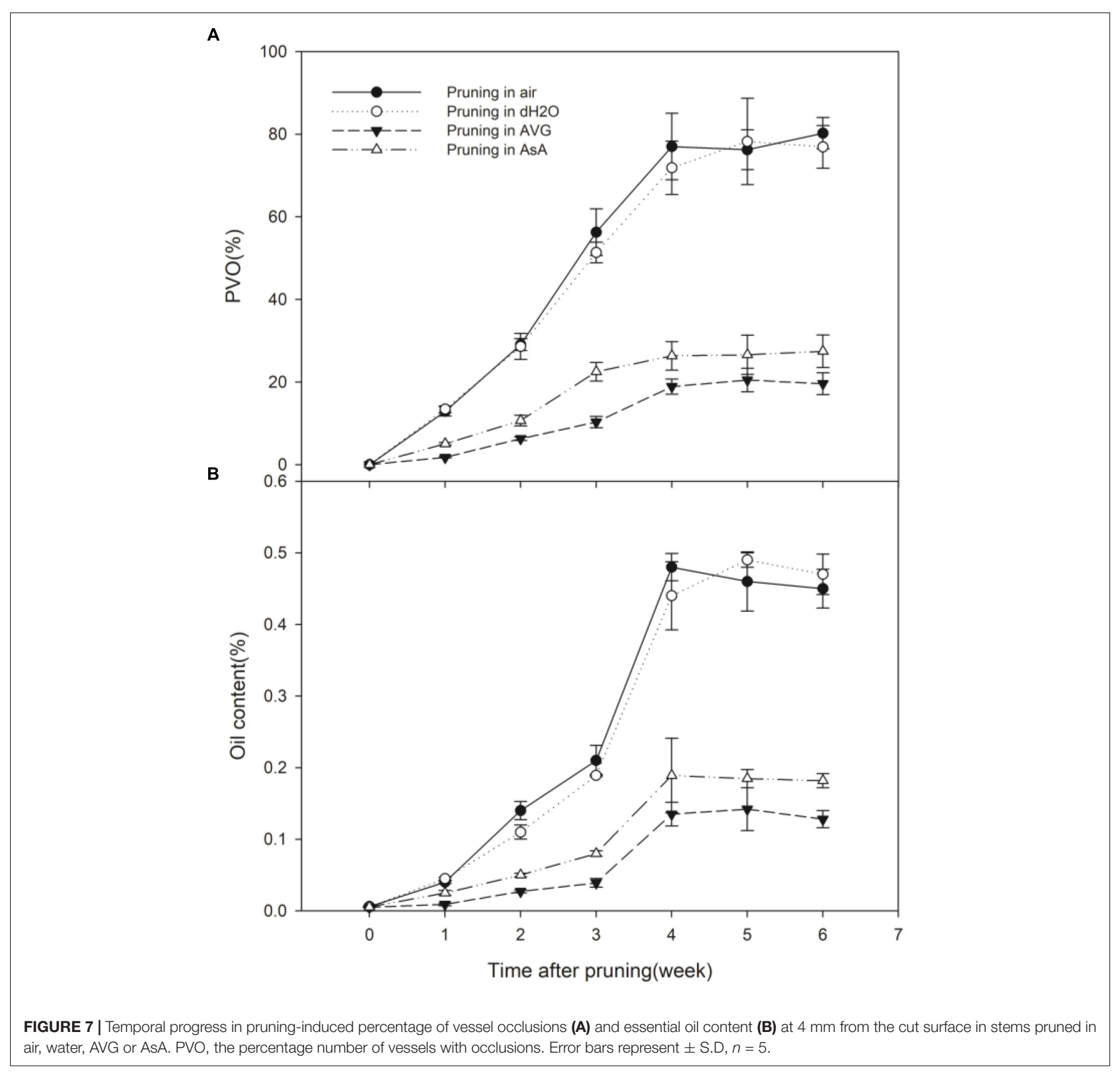

both treatments pruned in air and water and relative amounts of them were not statistically different. However, the volatiles of the treatment pruned in AVG or AsA were significantly different from the treatments in air and water. Only two and four volatiles were identified in stems pruned in AVG and AsA, respectively, which had fewer compounds than those in air and water (Table 2).

\section{DISCUSSION}

One of the prominent phenomena of plants in the response to external stimuli is the production pattern of ROS. Biphasic
$\mathrm{H}_{2} \mathrm{O}_{2}$ production with first a minor burst followed by a second major burst has been reported in several plants. In this study, there were two bursts of $\mathrm{H}_{2} \mathrm{O}_{2}$ production in $D$. odorifera stems after wounding, which was also observed in Arabidopsis and ryegrass (Le Deunff et al., 2004; Song et al., 2006). In addition, there were less vessel occlusions and amount of "Jiang Xiang" at $2 \mathrm{~mm}$ depth or at $\geq 6 \mathrm{~mm}$ due either high or low concentrations of $\mathrm{H}_{2} \mathrm{O}_{2}$ resulting in parenchyma cells necrosis. The medium $\mathrm{H}_{2} \mathrm{O}_{2}$ concentration at $4 \mathrm{~mm}$ depth induced the most vessel occlusions and "Jiang Xiang." This result was consistent with the fact that $\mathrm{H}_{2} \mathrm{O}_{2}$ plays a dual role in plants: it acts as a signal molecule at low concentrations and it leads to necrosis at high levels (Gill and Tuteja, 2010). 


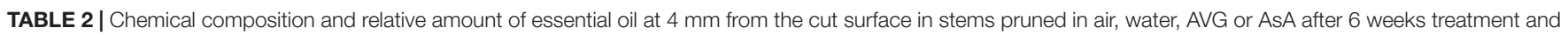
prior to pruning (CK).

\begin{tabular}{|c|c|c|c|c|c|c|}
\hline \multirow[t]{2}{*}{ No. } & \multirow[t]{2}{*}{ Compound name } & \multicolumn{5}{|c|}{ Relative amount (\%) } \\
\hline & & Pruning in air & Pruning in $\mathrm{dH}_{2} \mathrm{O}$ & Pruning in AVG & Pruning in AsA & CK \\
\hline 1 & (E)-.beta.-Famesene & $0.05 \pm 0.01 \mathrm{a}$ & $0.06 \pm 0.01 a$ & $-b$ & $-b$ & $-b$ \\
\hline 2 & .alpha.-Farnesene & $0.28 \pm 0.03 a$ & $0.32 \pm 0.03 a$ & $-b$ & $-b$ & $-b$ \\
\hline 3 & 2-Cyclohexen-1-ol, 2-methyl-5-(1-methylethenyl)-, cis- & $1.58 \pm 0.13 a$ & $1.67 \pm 0.15 a$ & $0.12 \pm 0.01 b$ & $0.26 \pm 0.01 b$ & $-\mathrm{C}$ \\
\hline 4 & 1,5-Heptadiene, 3,3-dimethyl-, (E)- & $1.49 \pm 0.09 a$ & $1.39 \pm 0.11 \mathrm{a}$ & $-\mathrm{C}$ & $0.11 \pm 0.02 b$ & $-\mathrm{C}$ \\
\hline 5 & 2-Isopropenyl-5-methylhex-4-enal & $0.67 \pm 0.04 a$ & $0.71 \pm 0.06 a$ & $-b$ & $-b$ & $-b$ \\
\hline 6 & 2-Cyclohexene-1-carboxaldehyde, 2,6,6-trimethyl- & $0.92 \pm 0.10 a$ & $0.81 \pm 0.09 a$ & $-\mathrm{C}$ & $0.53 \pm 0.03 b$ & $-\mathrm{C}$ \\
\hline 7 & Citronellol & $0.26 \pm 0.01 \mathrm{a}$ & $0.23 \pm 0.01 a$ & $-b$ & $-b$ & $-b$ \\
\hline 8 & Butanoic acid, 3-hexenyl ester, (Z)- & $1.76 \pm 0.12 \mathrm{a}$ & $1.89 \pm 0.15 a$ & $0.53 \pm 0.07 b$ & $0.69 \pm 0.05 b$ & $-c$ \\
\hline 9 & Nerolidol & $0.56 \pm 0.03 a$ & $0.48 \pm 0.04 a$ & $-b$ & $-b$ & $-b$ \\
\hline
\end{tabular}

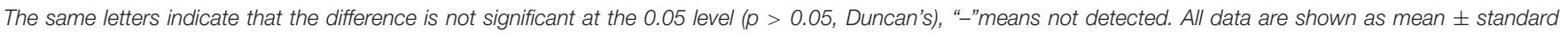
deviation.

Along the same pattern, ethylene production also burst twice in response to wounding. A similar pattern of woundinduced ethylene production was described in grape (Sun et al., 2007). Also, the hormone jasmonic acid was induced in a biphasic manner in response to wounding in pea seedlings (Yang et al., 2009). When wounding was conducted in air and in water, similar ethylene or $\mathrm{H}_{2} \mathrm{O}_{2}$ production was observed. It is understandable that treatments with ethylene or $\mathrm{H}_{2} \mathrm{O}_{2}$ inhibitors significantly inhibited ethylene or $\mathrm{H}_{2} \mathrm{O}_{2}$ production in wounded stems, respectively. In contrast, it is intriguing thing that AsA, the special scavenger of $\mathrm{H}_{2} \mathrm{O}_{2}$, also greatly inhibited ethylene production. This result indicated that the reduction in $\mathrm{H}_{2} \mathrm{O}_{2}$ inhibited ethylene production induced by wounding. Meanwhile, wound-induced $\mathrm{H}_{2} \mathrm{O}_{2}$ production was not suppressed in the presence of AVG, a specific inhibitor for ethylene biosynthesis. In addition, the first $\mathrm{H}_{2} \mathrm{O}_{2}$ burst at $2 \mathrm{~h}$ (Figure 3) and a significant ethylene production peak at $6 \mathrm{~h}$ (Figure 2) were observed. Thereafter, the second $\mathrm{H}_{2} \mathrm{O}_{2}$ burst and another ethylene production peak occurred at $12 \mathrm{~h}$ and $18 \mathrm{~h}$, respectively (Figures 2, 3). These results suggest that mechanical wounding induced biphasic $\mathrm{H}_{2} \mathrm{O}_{2}$ and ethylene production and each $\mathrm{H}_{2} \mathrm{O}_{2}$ burst was followed by an ethylene production peak. Hence, it appears that $\mathrm{H}_{2} \mathrm{O}_{2}$ production was required for ethylene production. Similar biphasic ROS or ethylene production was observed in plants subjected to other stresses such as ozone (Xie et al., 2011) and pathogen infection (Wi et al., 2012). After inoculation with Pseudomonas syringae, ethylene production in tobacco leaves followed a biphasic pattern reminiscent of $\mathrm{H}_{2} \mathrm{O}_{2}$ production (Mur et al., 2008). Wi et al. (2012) further provided evidence that a pathogeninduced oxidative burst was required as an upstream regulator of ethylene production in both phases. They suggested that the rapid transient increases in ROS generation followed by ROS-induced ethylene production act as a determinant of a hypersensitive response, whereas the later massive ROS burst and subsequent massive ethylene production act as a positive determinant of pathogen expansion and cell death in compatible interactions. Wi et al. (2012) also hypothesized that the late massive ROS burst stimulated higher biosynthesis of ethylene, which could promote disease susceptibility. In this process, the biphasic production of ethylene and ROS might be regulated by a self-amplifying loop (Wi et al., 2012). The issue of ROS signal specificity has recently received considerable attention. One possibility is that the specific features of ROS signaling could be perceived and decoded into specific responses, which determine gene expression patterns (Mittler et al., 2011). Despite these results, detailed studies on biphasic $\mathrm{H}_{2} \mathrm{O}_{2}$ or ethylene production have not been performed.

Nine major volatiles in wild "Jiang Xiang" (Ma et al., 2017) were identified in the essential oil extracted from stems pruned in air or water, none of which was found in the control samples (stems prior to pruning). As suppression of wound-induced ethylene or $\mathrm{H}_{2} \mathrm{O}_{2}$ production markedly reduced vessel occlusions and oil content, the kind and quantity of the volatiles in the treatments pruned in AVG or AsA decreased significantly compared to the treatments pruned in air and water. These results showed that wound-induced ethylene and $\mathrm{H}_{2} \mathrm{O}_{2}$ production were accompanied by vessel occlusions and accumulation of "Jiang Xiang" in pruned stems of D. odorifera. In other words, ethylene and $\mathrm{H}_{2} \mathrm{O}_{2}$ played vital roles in woundinduced vessel occlusions and accumulation of "Jiang Xiang" in D. odorifera.

This study demonstrated that wound-induced ethylene and $\mathrm{H}_{2} \mathrm{O}_{2}$ played vital roles in vessel occlusions and accumulation of "Jiang Xiang" in D. odorifera. They might regulate vessel occlusions and formation of "Jiang Xiang" in pruned stems of D. odorifera. Mechanical wound or fungal pathogen infection can induce structural barriers (including callose deposition, cell wall thickening and vessel occlusions), phytoalexins production, and induced expression of defense-related genes (Ahuja et al., 2012). For example, after fungal infection, rapid vessel occlusions by tyloses and formation of fungitoxic terpenoid aldehydes were observed in resistant cotton (Zhang et al., 1993; Daayf et al., 1997). It is hypothesized that pruning caused the production of wound signals (ethylene and $\mathrm{H}_{2} \mathrm{O}_{2}$ ). In this process, the $\mathrm{H}_{2} \mathrm{O}_{2}$ production stimulated higher biosynthesis of ethylene. Then synergistic biosynthesis of biphasic ethylene and $\mathrm{H}_{2} \mathrm{O}_{2}$ resulted in the formation of structural barriers (vessel occlusions) and 
formation of phytoalexins ("Jiang Xiang") that may contribute to physical barriers and chemical inhibition of microbes within vessels to prevent their spread. The PVO and amount of secondary substances increased with duration after pruning, and ultimately "Jiang Xiang" was formed in pruned stems of $D$. odorifera.

\section{CONCLUSION}

It was concluded that mechanical wounding resulted in the synergistic biosynthesis of biphasic $\mathrm{H}_{2} \mathrm{O}_{2}$ and ethylene, vessel occlusions and "Jiang Xiang" formation in D. odorifera. In this process, the $\mathrm{H}_{2} \mathrm{O}_{2}$ production stimulated higher biosynthesis of ethylene. Suppression of ethylene or $\mathrm{H}_{2} \mathrm{O}_{2}$ reduced the amount of vessel occlusions and "Jiang Xiang" production significantly. These results indicate that ethylene and $\mathrm{H}_{2} \mathrm{O}_{2}$ play vital roles in vessel occlusions and formation of "Jiang Xiang" in D. odorifera in response to mechanical wounding, and thus ethylene and $\mathrm{H}_{2} \mathrm{O}_{2}$ could be applied to induce formation of "Jiang Xiang" in D. odorifera. Further study is needed to explore the molecular

\section{REFERENCES}

Ahuja, I., Kissen, R., and Bones, A. M. (2012). Phytoalexins in defense against pathogens. Trends Plant Sci. 17, 73-90. doi: 10.1016/j.tplants.2011.11.002

Angelini, R., Tisi, A., Rea, G., Chen, M. M., Botta, M., Federico, R., et al. (2008). Involvement of polyamine oxidase in wound healing. Plant Physiol. 146, $162-$ 177. doi: 10.1104/pp.107.108902

Chen, X. Y., Gao, Y., and Li, W. M. (2012). Study on the correlation between the volatile constituents of Aquilaria sinensis and the inducing methods. China Pharm. 23, 1017-1020.

Cheng, Z. J., Kuo, S. C., Chan, S. C., Ko, F. N., and Teng, C. M. (1998). Antioxidant properties of butein isolated from Dalbergia odorifera. Biochim. Biophys. Acta 1392, 291-299. doi: 10.1016/S0005-2760(98)00043-5

Choi, C. W., Choi, Y. H., Cha, M.-R., Kim, Y. S., Yon, G., Kim, Y.-K., et al. (2009). Antitumor components isolated from the heartwood extract of Dalbergia odorifera. J. Korean Soc. Appl. Biol. Chem. 52, 375-379. doi: 10.3839/jksabc. 2009.067

Cui, Z. Y., Yang, Z. J., Xu, D. P., Xi, R. C., Zhang, N. N., Liu, X. J., et al. (2017). Stem respiration and chemical composition in Dalbergia odorifera plantations differing in soil moisture content. Aust. J. For. Sci. 134, 347-365.

Daayf, F., Nicole, M., Boher, B., Pando, A., and Geiger, J. P. (1997). Early vascular defense reactions of cotton roots infected with a defoliating mutant strain of Verticillium dahliae. Eur. J. Plant Pathol. 103, 125-136. doi: 10.1023/A: 1008620410471

D’Autréaux, B., and Toledano, M. B. (2007). ROS as signaling molecules: mechanisms that generate specificity in ROS homeostasis. Nat. Rev. Mol. Cell Biol. 8, 813-824. doi: 10.1038/nrm2256

Degousee, N., Triantaphylidès, C., and Montillet, J. L. (1994). Involvement of oxidative processes in the signaling mechanisms leading to the activation of glyceollin synthesis in soybean (Glycine max). Plant Physiol. 104, 945-952. doi: $10.1104 /$ pp.104.3.945

Dute, R. R., Duncan, K. M., and Duke, B. (1999). Tyloses in abscission scars of loblolly pine. Int. Assoc. Wood Anato J. 20, 67-74.

Gill, S. S., and Tuteja, N. (2010). Reactive oxygen species and antioxidant machinery in abiotic stress tolerance in crop plants. Plant Physiol. Biochem. 48, 909-930. doi: 10.1016/j.plaphy.2010.08.016

Guo, Z. J., Lamb, C., and Dixon, R. A. (1998). Potentiation of the oxidative burst and isoflavonoid phytoalexin accumulation by serine protease inhibitors. Plant Physiol. 118, 1487-1494. doi: 10.1104/pp.118.4.1487

Hong, K., Zhang, L., Zhan, R., Huang, B., Song, K., and Jia, Z. (2017). Identification and characterization of phospholipase $\mathrm{d}$ genes putatively involved in internal mechanism of ethylene and $\mathrm{H}_{2} \mathrm{O}_{2}$ regulation on formation of "Jiang Xiang" in D. odorifera.

\section{DATA AVAILABILITY}

All datasets generated for this study are included in the manuscript and/or the supplementary files.

\section{AUTHOR CONTRIBUTIONS}

ZC wrote the manuscript. ZY helped in the experiments. DX revised the manuscript.

\section{FUNDING}

This study was sponsored by the Fundamental Research Funds for the Central Non-profit Research Institution of Chinese Academy of Forestry (Grant No. CAFYBB2017ZX001-4).

browning of pineapple during postharvest storage. Front. Plant Sci. 8:913. doi: 10.3389/fpls.2017.00913

Hou, Z., Wang, L., Liu, J., Hou, L., and Liu, X. (2013). Hydrogen sulfide regulates ethylene-induced stomatal closure in Arabidopsis thaliana. J. Integr. Plant Biol. 55, 277-289. doi: 10.1111/jipb.12004

Hyodo, H., and Nishino, T. (1981). Wound-induced ethylene formation in albedo tissue of citrus fruit. Plant Physiol. 67, 421-423. doi: 10.1104/pp.67.3.421

Kato, M., Hayakawa, Y., Hyodo, H., Ikoma, Y., and Yano, M. (2000). Wound-induced ethylene synthesis and expression and formation of 1-aminocyclopropane-1-carboxylate (ACC) synthase, ACC oxidase, phenylalanine ammonia-lyase, and peroxidase in wounded mesocarp tissue of Cucurbita maxima. Plant Cell Physiol. 41, 440-447. doi: 10.1093/pcp/41. 4.440

Ke, D., and Saltveit, M. E. (2010). Wound-induced ethylene production, phenolic metabolism and susceptibility to russet spotting in iceberg lettuce. Physiol. Plantarum 76, 412-418. doi: 10.1111/j.1399-3054.1989.tb06212.x

Le Deunff, E., Davoine, C., Le Dantec, C., Billard, J. P., and Huault, C. (2004). Oxidative burst and expression of germin/oxo genes during wounding of ryegrass leaf blades: comparison with senescence of leaf sheaths. Plant J. 38, 421-431. doi: 10.1111/j.1365-313X.2004.02056.x

Levine, A., Tenhaken, R., Dixon, R., and Lamb, C. (1994). H2O2 from the oxidative burst orchestrates the plant hypersensitive disease resistance response. Cell 79, 583-593. doi: 10.1016/0092-8674(94)90544-4

Liu, X. J., Xu, D. P., Yang, Z. J., and Zhang, N. N. (2017). Geographic variations in seed germination of Dalbergia odorifera T. Chen in response to temperature. Ind. Crops Prod. 102, 45-50. doi: 10.1016/j.indcrop.2017. 03.027

Lorrain, S., Lin, B., Auriac, M. C., Kroj, T., Saindrenan, P., Nicole, M., et al. (2004). Vascular associated death, a novel GRAM domain-containing protein, is a regulator of cell death and defense responses in vascular tissues. Plant Cell 16, 2217-2232. doi: 10.1105/tpc.104.022038

Lucas, W. J., and Liu, C. M. (2017). The plant vascular system II: from essential functions in resource allocation, inter-organ communication and defense, to evolution of the monocot cambium. J. Integr. Plant Biol. 59, 354-355. doi: 10.1111/jipb.12551

Luna, E., Pastor, V., Robert, J., Flors, V., Mauch-Mani, B., and Ton, J. (2011). Callose deposition: a multifaceted plant defense response. Mol. Plant Microbe Interact. 24, 183-193. doi: 10.1094/MPMI-07-10-0149

Ma, Y. H., Jia, R. F., Yang, Z. J., Xu, D. P., Zhang, N. N., and Liu, X. J. (2017). Early growth evaluation on six-year-old Dalbergia odorifera T. Chen families. J. Central South Univ. For. Technol. 37, 42-47. 
Matsuda, F., Miyagawa, H., and Ueno, T. (2001). Involvement of reactive oxygen species in the induction of (S)-Np-coumaroyloctopamine accumulation by $\beta$ 1, 3-glucooligosaccharide elicitors in potato tuber tissues. Z. Naturforsch. C 56, 228-234. doi: 10.1515/znc-2001-3-410

Meng, H., Yang, Y., and Feng, J. D. (2010). The present situation and development of the introduction of Dalbergia odorifera T. Chen. Guangdong Agric. Sci. 37, 79-80.

Mittler, R., Vanderauwera, S., Suzuki, N., Miller, G., Tognetti, V. B., Vandepoele, K., et al. (2011). ROS signaling: the new wave? Trends Plant Sci. 16, 300-309. doi: 10.1016/j.tplants.2011.03.007

Mur, L. A. J., Laarhoven, L. J. J., Harren, F. J. M., Hall, M. A., and Smith, A. R. (2008). Nitric oxide interacts with salicylate to regulate biphasic ethylene production during the hypersensitive response. Plant Physiol. 148, 1537-1546. doi: $10.1104 /$ pp. 108.12440

O’Donnell, P. J., Calvert, C., Atzorn, R., Wasternack, C., Hmo, L., and Bowles, D. J. (1996). Ethylene as a signal mediating the wound response of tomato plants. Science 274, 1914-1917. doi: 10.1126/science.274.5294. 1914

Orozco-Cardenas, M., and Ryan, C. A. (1999). Hydrogen peroxide is generated systemically in plant leaves by wounding and systemin via the octadecanoid pathway. Proc. Natl. Acad. Sci. U.S.A. 96, 6553-6557. doi: 10.1073/pnas.96.11. 6553

Perrone, S. T., McDonald, K. L., Sutherland, M. W., and Guest, D. I. (2003). Superoxide release is necessary for phytoalexin accumulation in Nicotiana tabacum cells during the expression of cultivar-race and non-host resistance towards Phytophthora spp. Physiol. Mol. Plant Pathol. 6, 127-135. doi: 10.1016/ S0885-5765(03)00026-2

Ross, C., Kupper, F. C., and Jacobs, R. S. (2006). Involvement of reactive oxygen species and reactive nitrogen species in the wound response of Dasycladus vermicularis. Chem. Biol. 13, 353-364. doi: 10.1016/j.chembiol.2006. 01.009

Saitoh, T., Ohtani, J., and Fukazawa, K. (1993). The occurrence and morphology of tyloses and gums in the vessels of Japanese hardwoods. Int. Assoc. Wood Anato J. 14, 359-371. doi: 10.1163/22941932-900 00590

Savatin, D. V., Gramegna, G., Modesti, V., and Cervone, F. (2014). Wounding in the plant tissue: the defense of a dangerous passage. Front. Plant Sci. 5:470. doi: $10.3389 /$ fpls.2014.00470

Song, C. J., Steinebrunner, I., Wang, X., Stout, S. C., and Roux, S. J. (2006). Extracellular ATP induces the accumulation of superoxide via NADPH oxidases in Arabidopsis. Plant Physiol. 140, 1222-1232. doi: 10.1104/pp.105.073072

Sugiyama, A., Zhu, B. M., Takahara, A., Satoh, Y., and Hashimoto, K. (2002). Cardiac effects of Salvia miltiorrhiza/Dalbergia odorifera mixture, an intravenously applicable Chinese medicine widely used for patients with ischemic heart disease in China. Circ. J. 66, 182-184. doi: 10.1253/circj. 66.182

Sun, Q., Rost, T. L., Reid, M. S., and Matthews, M. A. (2007). Ethylene and not embolism is required for wound-induced tylose development in stems of grapevines. Plant Physiol. 145, 1629-1636. doi: 10.1104/pp.107.100537
Van Doorn, W. G., Harkema, H., and Otma, E. (1991). Is vascular blockage in stems of cut lilac flowers mediated by ethylene? Acta Hortic. 298, 177-182. doi: 10.17660/ActaHortic.1991.298.21

Wang, D. G., Zhang, N. N., Yang, Z. J., Liu, X. J., Hong, Z., and Xu, D. P. (2016). Study on resistance ability of Aquilaria sinensis trees under artificial induction. J. South China Agric. Univ. 37, 70-76.

Wang, W., Weng, X. C., and Cheng, D. L. (2000). Antioxidant activities of natural phenolic components from Dalbergia odorifera T. Chen. Food Chem. 71, 45-49. doi: 10.1016/S0308-8146(00)00123-0

Wei, M., Lin, L., Qiu, J. Y., Cai, Y. W., Lu, A. N., Yuan, L., et al. (2000). Winddamage effects on quality of heartwood of Santalum album. China J. Chin. Mater. Med. 25, 710-713.

Wi, S. J., Ji, N. R., and Park, K. Y. (2012). Synergistic biosynthesis of biphasic ethylene and reactive oxygen species in response to hemibiotrophic phytophthora parasitica in tobacco plants. Plant Physiol. 159, 251-265. doi: 10.1104/pp.112.194654

Xie, Y. J., Xu, S., Han, B., Wu, M. Z., Yuan, X. X., Han, Y., et al. (2011). Evidence of Arabidopsis salt acclimation induced by upregulation of HY1 and the regulatory role of $\mathrm{RbohD}$-derived reactive oxygen species synthesis. Plant J. 66, 280-292. doi: 10.1111/j.1365-313X.2011.04488.x

Yang, H. R., Tang, K., Liu, H. T., Pan, Q. H., and Huang, W. D. (2009). Jasmonic acid is induced in a biphasic manner in response of pea seedlings to wounding. J. Integr. Plant Biol. 51, 562-573. doi: 10.1111/j.1744-7909.2009.00832.x

Yukihiro, G., Fumiyuki, K., Masaaki, S., and Ushio, S. (1985). Inhibitors of prostaglandin biosynthesis from Dalbergia odorifera. Chem. Pharm. Bull. 40, 2452-2457.

Zhang, J., Mace, M. E., Stipanovic, R. D., and Bell, A. A. (1993). Production and fungitoxicity of the terpenoid phytoalexins in cotton inoculated with Fusarium oxysporum f. sp. vasinfectum. J. Phytopathol. 139, 247-252. doi: 10.1111/j.14390434.1993.tb01423.x

Zhang, Z., Yang, Y., Meng, H., Sui, C., Wei, J. H., and Chen, H. Q. (2010). Advances in studies on mechanism of agarwood formation in Aquilaria sinensis and its hypothesis of agarwood formation induced by defense response. Chin. Tradit. Herb. Drugs 41, 156-160.

Zhang, Z., Zhang, X., Yang, Y., Wei, J. H., Meng, H., Gao, Z. H., et al. (2014). Hydrogen peroxide induces vessel occlusions and stimulates sesquiterpenes accumulation in stems of Aquilaria sinensis. Plant growth Regul. 72, 81-87. doi: $10.1007 /$ s10725-013-9838-z

Conflict of Interest Statement: The authors declare that the research was conducted in the absence of any commercial or financial relationships that could be construed as a potential conflict of interest.

Copyright (c) 2019 Cui, Yang and Xu. This is an open-access article distributed under the terms of the Creative Commons Attribution License (CC BY). The use, distribution or reproduction in other forums is permitted, provided the original author(s) and the copyright owner(s) are credited and that the original publication in this journal is cited, in accordance with accepted academic practice. No use, distribution or reproduction is permitted which does not comply with these terms. 